http://jmscr.igmpublication.org/home/ ISSN (e)-2347-176x ISSN (p) 2455-0450 crossref DOI: https://dx.doi.org/10.18535/jmscr/v8i1.105

\title{
Combined General Anaesthesia and Spinal Anaesthesia versus General Anaesthesia only in total Laparascopic Hysterectomy- A Comparative Study
}

\author{
Authors \\ Pradipta Kumar Patel ${ }^{1}$, Dulal Kishun Soren ${ }^{2}$, Subhadipta Panigrahi $^{3}$, Pujarini Beuria ${ }^{4}$ \\ ${ }^{1,2}$ Associate Professor, Department of Anaesthesiology, VIMSAR \\ ${ }^{3,4}$ Junior Resident, Department of Anaesthesiology, VIMSAR
}

\begin{abstract}
Background and Objectives: Spinal anaesthesia was combined with general anaesthesia for achieving hemodynamic stability in laparoscopic hysterectomy. The aim of our study was to evaluate the impact of SA combined with GA in maintaining hemodynamic stability in laparoscopic hysterectomy. The secondary outcomes studied were requirement of inhaled anaesthetics, vasodilators.

Material and Methods: We conducted a prospective randomized study in ASAI/II patients posted for laparoscopic hysterectomy, after taking proper written consent. Patients were randomly assigned to receive SA with GA (group SGA) or plain GA (group GA). Group SGA received $10 \mathrm{mg}$ of $0.5 \%$ Bupivacaine (heavy) for SA. GA was administerd using conventional balanced technique. Maintenance was carried out with nitrous oxide, oxygen, and isoflurane. Comparison of hemodynamic parameters was carried out during creation of pneumoperitoneum and thereafter. Total isoflurane requirement, need of vasodilators and surgeon satisfaction were also studied.
\end{abstract}

Results: Patients in group SGA maintained stable and acceptable MAP values throughout pneumoperitoneum. The difference as compared to GA was statistically significant $(p<0.01)$. Group GA showed additional requirement of Nitroglycerine infusion and higher concentration of isoflourane. Group SGA showed greater surgeon satisfaction as compared to group GA.

Conclusion: The hemodynamic repercussions during pneumoperitoneum can be effectively attenuated by combining SA and GA, without any adverse effects.

Keywords: General anaesthesia, hemodynamics, laparoscopy, pneumoperitoneum, spinal anaesthesia.

\section{Introduction}

This is a modern era of surgery which has witnessed many new and innovative approaches encompassing minimal intervention. Laparoscopic surgery occupies the centre stage in the modern era. Laparoscopic surgery is nowadays a common daily-performed procedure worldwide, replacing many types of open surgeries. Laparoscopy which avoid large abdominal incisions, allow a significant reduction in surgical trauma, postoperative

morbidity,

pulmonary complications, pain opioid requirements, and shortened hospital stay, moved many procedures into the outpatient arena, and perhaps reduced overall cost. $^{[1-3]}$

However, laparoscopic surgery also introduced new challenges for anaesthesiologists due to the effects of pneumoperitoneum on circulation and respiratory function, the risk of venous gas embolism, and the pathophysiologic changes 
caused by extraperitoneal gas insufflation and extremes of patient positioning. ${ }^{[4,5]}$ The gradual shift of laparoscopy to include more complicated surgical procedures resulted in modifications of existing anaesthetic techniques. Thus the surgeries which were performed under regional anaesthesia traditionally went under the domain of general anaesthesia thereby negating some advantages of minimal access surgery as general anaesthesia have some disadvantages linked to it. Laparoscopic surgeries are normally performed under general anaesthesia with endotracheal intubation to prevent aspiration and respiratory embarrassment secondary to induction of pneumoperitoneum and also to prevent discomfort and shoulder pain due to stretching of the diaphragm in patients who are awake during the procedure. Consequently, the use of regional anaesthesia (RA) in laparoscopic surgery has been limited to patients at high risk for GA due to severe coexisting pulmonary, cardiac, or other disease. ${ }^{[5,8,9,11]}$ Regional anaesthesia has also been used for laparoscopy in fit patients in combination with general anaesthesia for the pain-free postoperative period. Recent evidence suggests that regional anaesthesia has a significant role in the care of patients undergoing laparoscopy. ${ }^{[6]}$ There are many published reports of laparoscopic cholecystectomy and inguinal hernia repair under spinal anaesthesia and epidural anaesthesia. ${ }^{[7,10]}$

Laparoscopic surgeries are performed under both spinal anaesthesia (SA) and general anaesthesia (GA), depending on patient's selection, laparoscopist's skill, and anaesthesiologist's comfort. GA, by convention, remains the mainstay for all kinds of laparoscopic surgeries. However, the unopposed increase in systemic vascular resistance (SVR) associated with pneumoperitoneum has to be managed by increasing anaesthetic concentrations and, at times, administering vasodilators. This eventually leads to unnecessary deepening of anaesthesia, delayed awakening, and does not prove cost effective. While spinal anaesthesia is being utilized for short laparoscopic procedures, the sympathectomy counteracts the increased SVR. However, with prolonged pneumoperitoneum time, patient's discomfort becomes the limiting factor.

Concomitant use of two anesthesia techniques for better hemodynamic variables is a widely accepted method. ${ }^{[6]}$ Adding spinal anaesthesia to general anaesthesia can attenuate the hemodynamic changes associated with pneumoinsufflation by decreasing SVR, mean arterial blood pressure (MAP) and maintaining cardiac index as well as decrease the requirements of various anaesthetic agents. It also improves surgical field by contraction of bowels due to sympathetic blockade. When spinal anaesthesia is utilized, vaginal dissection can be carried out with minimum anesthetic agents sufficient to prevent awareness. ${ }^{[12-16]}$

Motivated by these facts, the present study was designed to compare the combination of SA and GA with plain GA in patients undergoing laparoscopic hysterectomy, with the hypothesis that sympathectomy of spinal anaesthesia overcomes the hemodynamic response of pneumoperitoneum. The primary outcome of our study was to find the impact of spinal anaesthesia on hemodynamic repercussions of pneumoperitoneum. The secondary outcomes to be studied were requirement of inhalational agents, vasodilators and residual effects of spinal anaesthesia.

\section{Materials and Methods}

This is a prospective randomized control study conducted in patients undergoing total laparoscopic hysterectomy in department of O\&G, VIMSAR Burla between January 2019 to June 2019. Based on previous study, a sample size of 58 was required to show a difference of $20 \%$ in mean arterial pressure, considering an error margin of $5 \%$ and a power of $80 \%$. Considering a dropout rate of $10 \%$, a total of 64 patients were enrolled in the study. Sample size was calculated using Clin Clac .com (2018-ClinClac LLC). After obtaining approval from the institutional ethical 
committee and written informed consent, 64 female patients of age 18-60 years, ASA grade I and II and 40-70 kg body weight undergoing total laparoscopic hysterectomy were included in the study. Patients with ASA physical status III/IV, history of allergy to drugs, history of psychiatric illness, coagulopathy, local infection at injection site, any spinal deformity and Rapid drop in blood pressure after spinal anaesthesia requiring vasopressor infusion were excluded from the study. Patients were randomly assigned to one of the two groups, as decided by computer generated randomization schedule.

GROUP SA+GA: Receiving both GA and SA GROUP GA: Receiving only GA

After proper pre-anaesthetic check-up, all patients were given Alprazolam $0.5 \mathrm{mg}$ and Ranitidine $150 \mathrm{mg}$ orally on the day before surgery and were kept nil per orally for a minimum duration of 8 hours. In the operation theatre, monitor showing heart rate, non-invasive blood pressure, ECG and oxygen saturation probe were attached. Baseline parameters like heart rate, mean Arterial pressure, oxygen saturation and ECG were recorded. IV ringer's lactate was started after obtaining venous access.

Maintaining asepsis, and after proper skin preparations, Spinal anaesthesia was administered by a 25G Quincke's spinal needle in L3-L4 intervertebral space in left lateral position. After free flow of clear CSF 10mg hyperbaric Bupivacaine $0.5 \%$ injected. Patients were immediately made supine. Onset of sensory was checked by pin prick and motor block assessment was done by modified Bromage scale. After waiting for 10 mins patients were induced for GA. Patients were premedicated with inj glycopyrollate, inj midazolam, and inj Nalbuphine intravenously. All patients received ondansetron $4 \mathrm{mg}$ intra-operatively. Anaesthesia induced with inj Propofol $(2 \mathrm{mg} / \mathrm{kg}$ ), vecuronium $0.1 \mathrm{mg} / \mathrm{kg}$ was given to facilitate intubation.

Anaesthesia was maintained by nitrous oxide and oxygen mixture (2:1), isoflurane, and vecuronium. Isoflurane was titrated to maintain MAP and HR within 20 percent of baseline and also Bispectral index between 40 and 60 . Nitroglycerine was used as a rescue drug where MAP could not be maintained by Isoflurane titration. The average total volume of isoflurane liquid was calculated and compared in both the groups. Similarly, HR, MAP, Total duration of surgery, changes in BIS were also compared in both groups. A Numerical Rating scale was used to rate surgeon's satisfaction and compared in both the groups

\section{Observations \& Results}

All data was collected in a pre-described proforma and tabulated using Microsoft Excel 2018. Statistical analysis was performed process using IBM SPSS Statistics 24.0, SPSS South Asia Pvt. Ltd. Categorical data was compared using the chisquare test. Parametric data were analysed using independent sample ' $t$ ' test. Non-parametric data were analysed using Chi-square test and Mannwhitney test. The cutoff value of significance for testing of hypothesis was $\leq 0.05$.

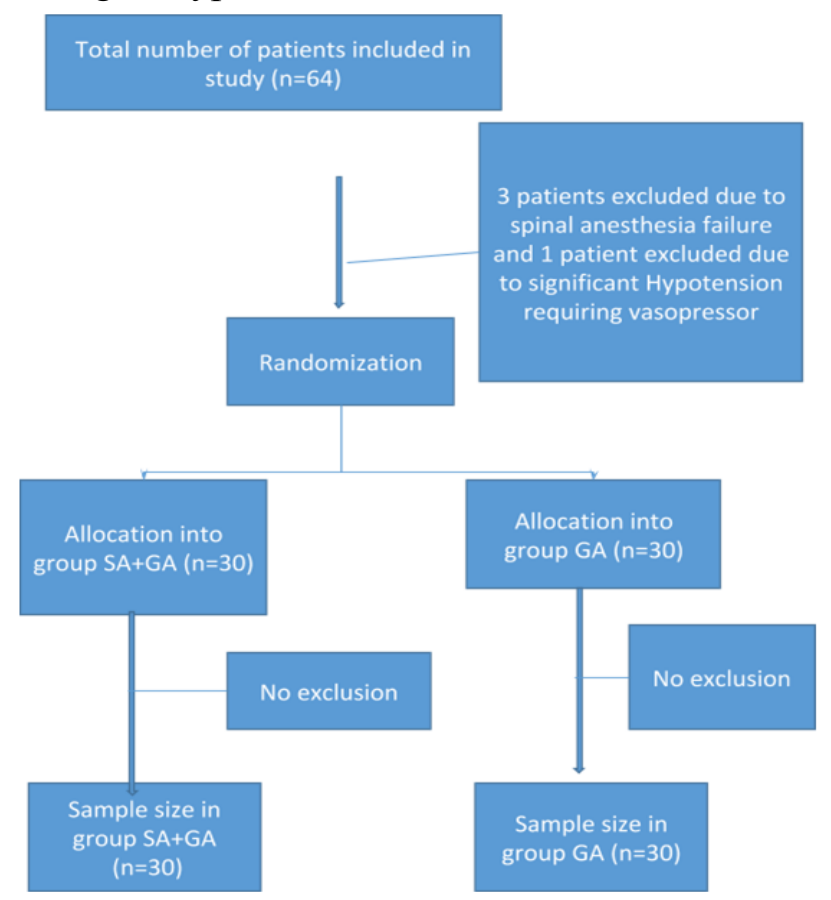

Fig 1- Consort diagram

The comparison between demographic data (age, weight, height, BMI) in both the groups is shown in table-1, fig 2,3,4,5. Both the groups were comparable in terms of demographic profile with no statistical significance. 


\section{JMSCR Vol||08||Issue||01||Page 674-681||January}

Table 1 Age profile of study subjects

\begin{tabular}{|l|c|c|}
\hline Descriptive Statistics of Age & SA+GA & GA \\
\hline N (No. of Subjects) & 30 & 30 \\
\hline Mean \pm SD & $48.73 \pm 3.38$ & $\begin{array}{c}49.60 \pm 3.06 \\
(\mathrm{p}=0.302)^{*}\end{array}$ \\
\hline Q1 (1 ${ }^{\text {st }}$ Quartile) & 46 & 47 \\
\hline Q2 (Median) & 48 & 50 \\
\hline Q3 $\left(^{\text {rd }}\right.$ Quartile) & 52 & 52 \\
\hline Minimum & 43 & 42 \\
\hline Maximum & 55 & 55 \\
\hline *p value for comparison of mean age SA+GA vrs. GA & \\
\hline
\end{tabular}

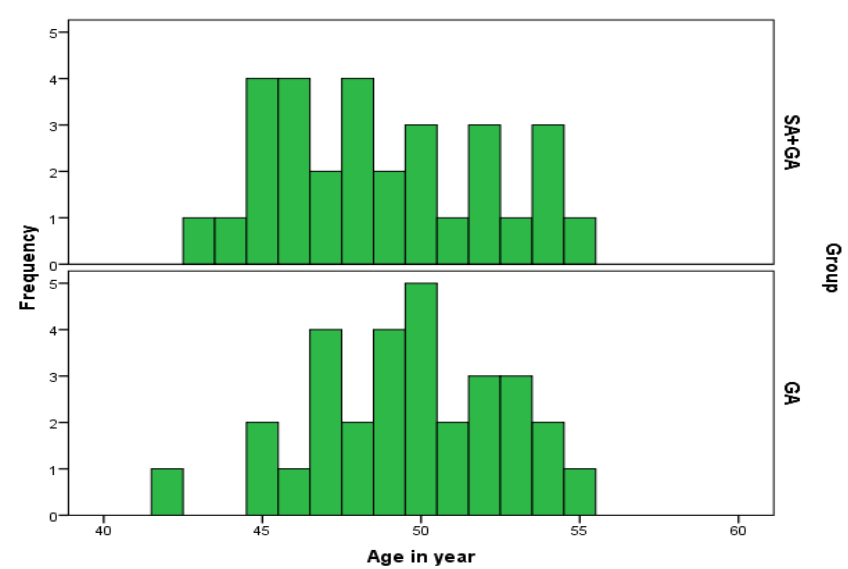

Fig-2 Frequency distribution of age
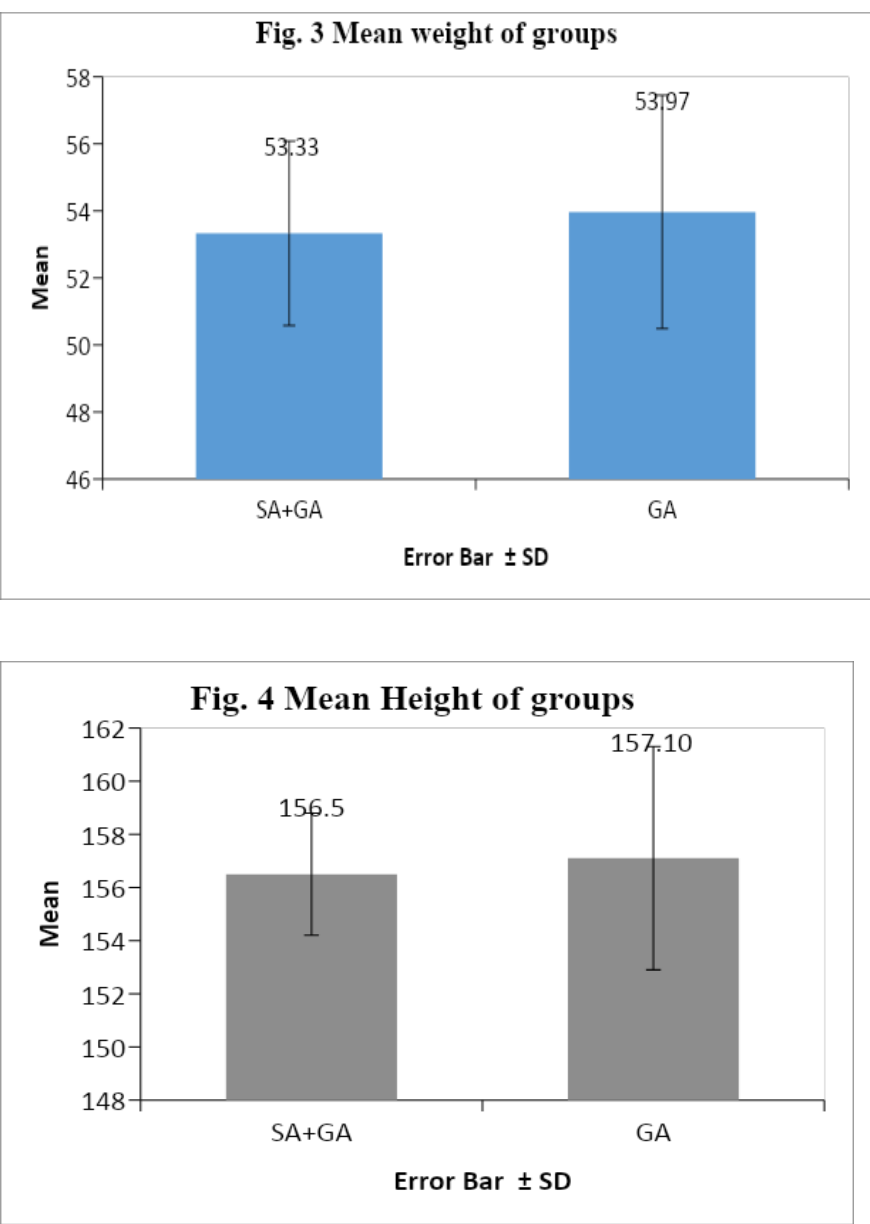

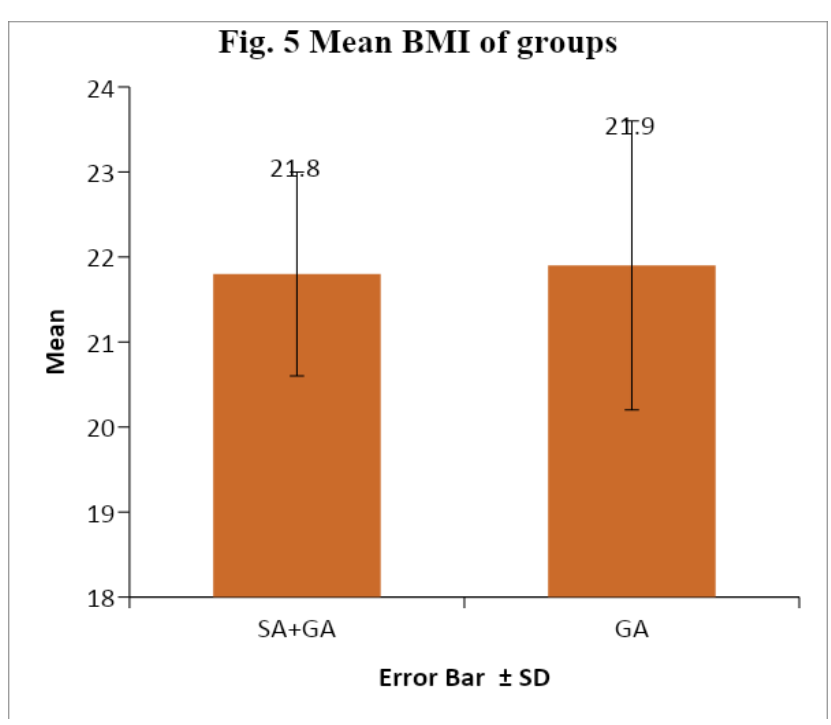

Figure 6 shows comparision of change in heart rate over baseline at various time intervals. Increase in HR by $20 \%$ from the baseline was found in almost all follow ups and were significantly different $(\mathrm{p}<0.05)$. Similarly, figure 7 depicts comparison of MAP over baseline at various time intervals. It is evident from the figure that variation in MAP was greater in GA group as compared to SA+GA group and were statistically significant $(\mathrm{p}<0.05)$. 


\section{JMSCR Vol||08||Issue||01||Page 674-681||January}
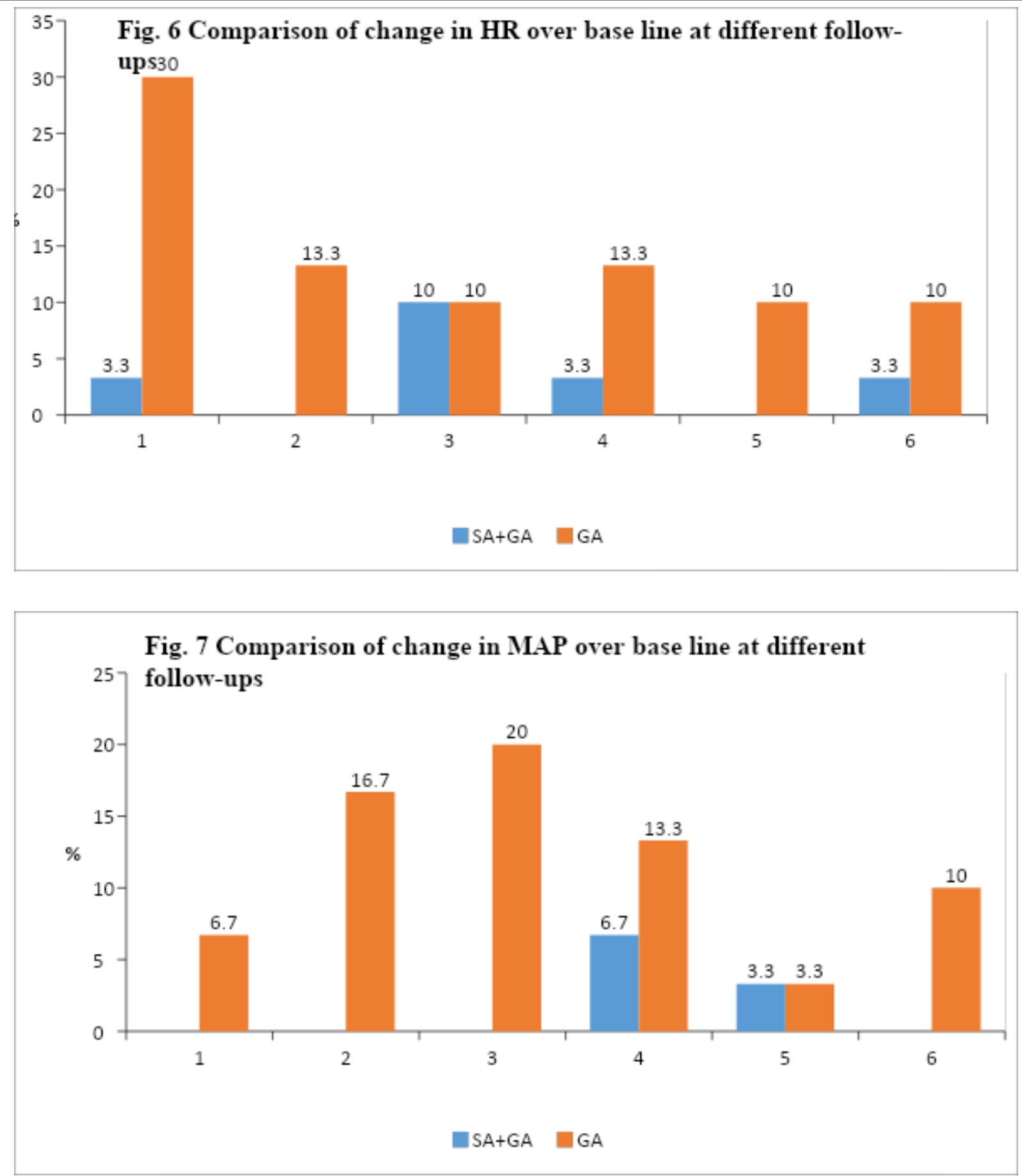

Table 2 and Figure 8 shows comparison of volume of vaporizer used to maintain BIS between 40 and 60 , in both the groups. Mean volume of isoflurane used in group SA+GA was
$4.6+/-0.7 \mathrm{ml}$ as compared to $10+/-1.1 \mathrm{ml}$ in $\mathrm{GA}$ group. It was comparable and statistically significant $(\mathrm{p}=0.000)$.

Table 2 Comparison of volume of vapouriser liquid used to maintain BIS between 40 and 60

\begin{tabular}{|l|c|c|c|c|c|c|}
\hline Group & N & Mean \pm SD & Q1 & Q2(median) & Q3 & Mann-Whitney U 'p' value \\
\hline SA+GA & 30 & $4.6 \pm 0.7$ & 4.2 & 4.5 & 5 & 0.000 \\
\hline GA & 30 & $10.0 \pm 1.1$ & 9.3 & 10.3 & 10.8 & \\
\hline
\end{tabular}


Fig. 8 Comparison of volume of vapouriser liquid used to maintain BIS between 40 and 60

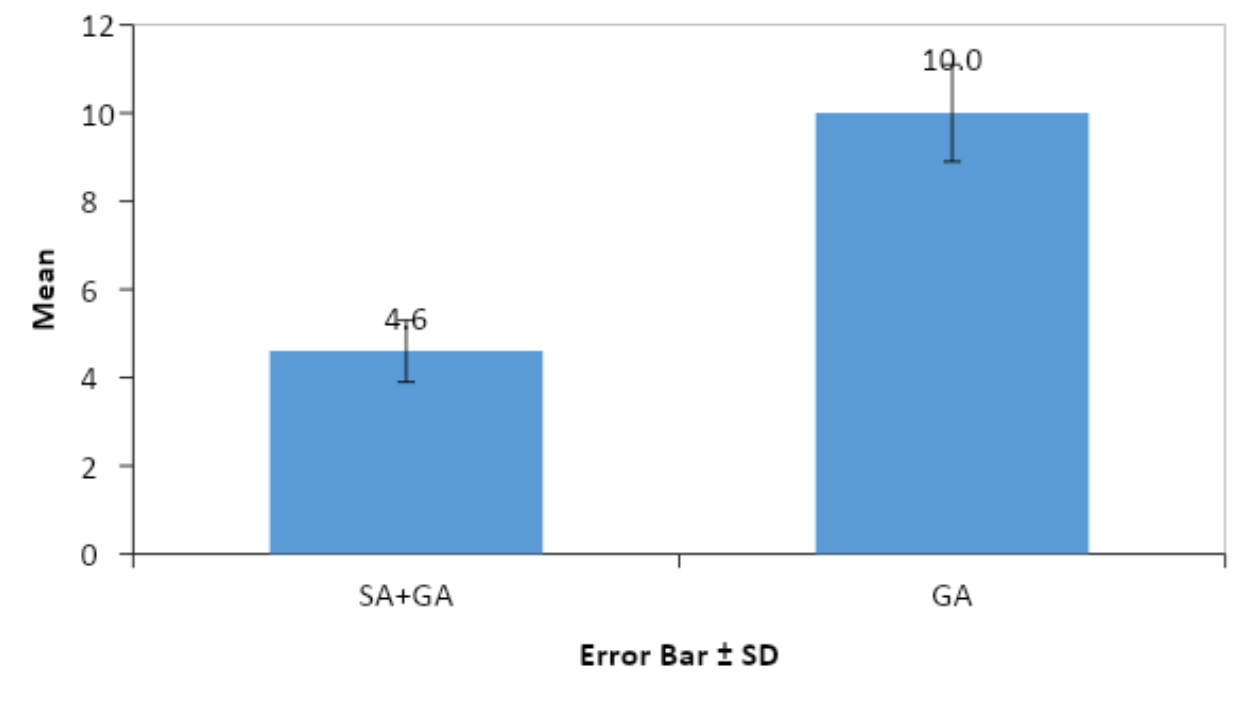

Table 3 and figure 9 shows the comparision between surgeon satisfaction in both the groups using a Numerical Rating Scale (NRS). Average rating given by surgeon in SA+GA group was 7.3
+/- 0.5 as compared to 5.3+/- 0.5 in GA group. It was comparable and statistically significant $(\mathrm{p}=0.000)$

Table 3 Comparison of NRS from 1 to 10 as per surgeons satisfaction

\begin{tabular}{|l|c|c|c|c|c|c|}
\hline Group & N & Mean \pm SD & Q1 & Q2(median) & Q3 & $\begin{array}{c}\text { Mann-Whitney U } \\
\text { 'p' value }\end{array}$ \\
\hline SA+GA & 30 & $7.3 \pm 0.5$ & 7 & 7 & 8 & 0.000 \\
\hline GA & 30 & $5.3 \pm 0.5$ & 5 & 5 & 6 & 0.00 \\
\hline
\end{tabular}

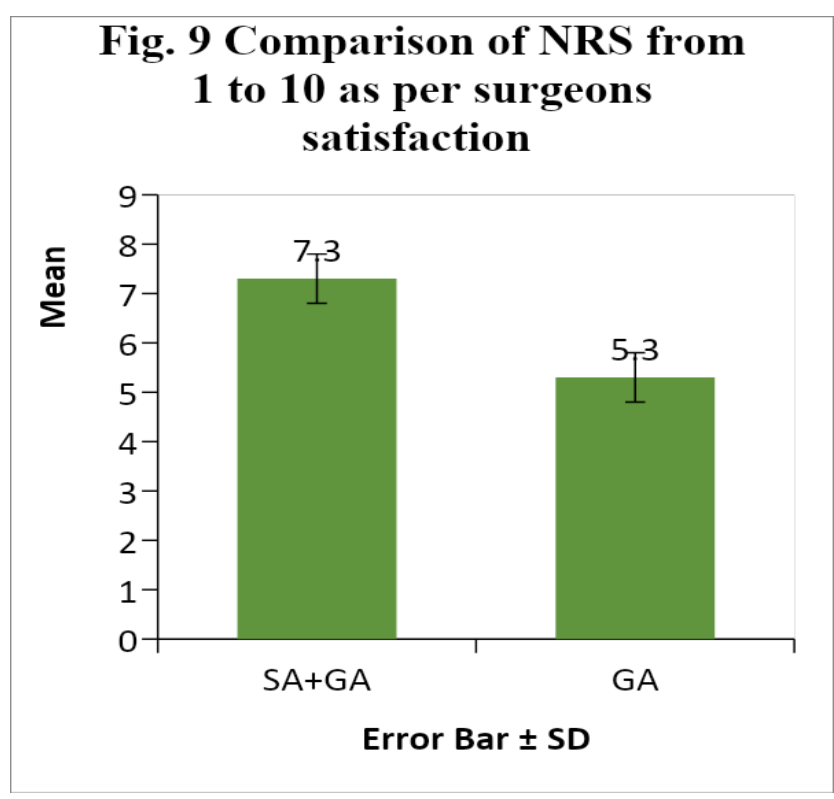

The changes in BIS were compared in both groups. In group GA, the excess concentration of isoflurane administered to counteract the increased MAP resulted in unnecessary deepening of anaesthesia (BIS<40). But in group $\mathrm{SA}+\mathrm{GA}$, BIS was maintained between 40-60 with only minimal concentration of isoflurane.

\section{Discussion}

GA has remained the most accepted modality of anaesthesia for laparoscopic surgeries. But under GA the hemodynamic derangements during pneumoperitoneum have to be managed by either increasing anaesthetic concentration or by administering vasodilators. The former leads to unnecessary deepening of anaesthesia and the later may cause awareness intraoperatively. The need for an additional modality of anaesthesia with GA has led to studying various other options over the years. One of the most successfully used anaesthesia with GA is spinal anaesthesia. Various studies regarding its feasibility, patient comfort after the procedure, incidence of postoperative 
complications, recovery from anaesthesia, ambulation, hospital stay and cost effectiveness due to decreased requirement of analgesia, have been conducted showing that it is indeed a good alternative to only GA, better than a sole, GA in various situations. The regional techniques have been shown to attenuate the metabolic and endocrine responses. Our study demonstrates that the hemodynamic instability of pneumoperitoneum can be successfully managed with a combined SA and GA technique. The combination of these two techniques provided better cardiocirculatory stability than GA alone in Laparoscopic Hysterectomy. Pneumoperitoneum during laparoscopic surgery leads to significant hemodynamic changes like increase in SVR and MAP often necessitating therapeutic intervention. [17, 18] When GA is combined with SA, the sympatholysis caused by SA may limit the rise in SVR, thus overcoming the increased MAP. This finding was confirmed in our study where MAP was well maintained in group $\mathrm{SA}+\mathrm{GA}$ as against only GA group.

Various pharmacological agents like betablockers, nitroglycerine, and alpha 2 agonists can be used to counteract these changes, but they have their own disadvantages. ${ }^{[19,20]}$ Combining two anaesthesia techniques to add their advantages and limit the side effects of each is not new. [21] Lucheti et al. studied the combination of epidural and general anaesthesia for laparoscopic cholecystectomy and concluded the combination to be safe and effective. ${ }^{[22]}$ Encouraged by this, we conducted a prospective, randomized study to examine and evaluate whether combining SA and GA improved hemodynamic stability in patients undergoing laparoscopoic hysterectomy.

The lower use of isoflurane led to early awakening and extubation in group $\mathrm{SA}+\mathrm{GA}$ as compared to group GA. This finding is supported by a study conducted by Lerou and Booji. ${ }^{[23]}$ The unopposed parasympathetic outflow following SA causes increased bowel contractility, resulting in better operative field ${ }^{[24]}$.This led to decreased duration of surgery time and increased surgeon satisfaction(basing on NRS obtained from surgeons).Volume of isoflurane liquid used was quite less in SA+GA group. So there can be a cut off in the cost required for surgery. The limitation of our study was the small number of patients studied undergoing one laparoscopic procedure, and only ASA grade I/II patients were included.

\section{Conclusion}

Our initial experience with laparoscopic surgery under combined spinal with GA appears promising. To conclude, the hemodynamic derangement during pneumoperitoneum can be effectively attenuated by combining SA and GA without any adverse effects. So, we recommend this conjunction of two anaesthesia techniques in patients undergoing laparoscopic hysterectomy.

\section{References}

1. Harrell AG, Lincourt AE, Novitsky YW, et al. Advantages of laparoscopic appendectomy in the elderly. Am Surg. 2006;72:474e480.

2. Hendolin HI, Paakonen ME, Alhava EM, Tarvainen R, Kemppinen $\mathrm{T}$, Lahtinen $\mathrm{P}$. Laparoscopic or open cholecystectomy: a prospective randomised trial to compare postoperative pain, pulmonary function and stress response. Eur J Surg. 2000;166:394e399.

3. Zacks SL, Sandler RS, Rutledge R, Brown Jr RS. A population based cohort study comparing laparoscopic cholecystectomy and open cholecystectomy. Am J Gastroenterol. 2002;97:334e340.

4. Chui PT, Gin T, Oh TE. Anaesthesia for laparoscopic general surgery. Anaesth Intensive Care. 1993;21:163e171.

5. Gerges FJ, Kanazi GE, Jabbour-Khoury SI. Anesthesia for laparoscopy: a Review. J Clin Anesth. 2006;18:67e78.

6. Collins LM, Vaghadia H. Regional anaesthesia for laparoscopy. Anesthesiol Clin N Am. 2001;19:43e55.

7. Van Zundert AA, Stultiens G, Jakimowicz JJ, et al. Laparoscopic cholecystectomy under 
segmental thoracic spinal anaesthesia: a feasibility study. $\mathrm{Br} \mathrm{J}$ Anaesth. 2007;98:682e686.

8. Gramatica L, Brasesco OE, Luna AM, et al. Laparoscopic cholecystectomy performed under regional anesthesia in patients with chronic obstructive pulmonary disease. Surg Endosc. 2002;16:472e475.

9. Pursnani KG, Bazza Y, Calleja M, Mughal MM. Laparoscopic cholecystectomy under epidural anesthesia in patients with chronic respiratory disease. Surg Endosc. 1998;12: $1426 \mathrm{e} 1428$.

10. Chowbey PK, Sood J, Vashistha A, et al. Extraperitoneal endoscopic groin hernia repair under epidural anesthesia. Surg Laparosc Endosc Percutan Tech. 2003;13:185e190.

11. Sulemanji DS, Donmez A, Arslan G. Epidural anaesthesia for laparoscopic cholecystectomy in a patient with scleroderma. Br J Anaesth. 2006;97:749.

12. Tiwari S, Chauhan A, Chaterjee P, Alam M. Laparoscopic cholecystectomy under spinal anaesthesia: a prospective, randomised study. J Minimal Access Surg. 2013;2(9):65e71.

13. Vretzakis G, Bareka M, Aretha D, Karanikolas M. Regional anesthesia for laparoscopic surgery: a narrative review. J Anesth. 2014;28(3):429e446.

14. Kar M, Kar JK, Debnath B. Experience of laparoscopic cholecystectomy under spinal anesthesia with low-pressure pneumoperitoneume prospective study of 300 cases. Saudi J Gastroenterol. 2011;17:203e207.

15. Pratsas K, Georgopoulou S, Bareka M, Ieropoulos C, Flossos A, Vretzakis G. The feasibility of laparoscopic general surgery under regional Anaesthesia. Greek E-J Perioper Med.2010;8:1e10.

16. Mane RS, Patil MC, Kedareshvara KS, Sanikop CS. Combined spinal epidural anesthesia for laparoscopic appendectomy in adults: a case series. Saudi J Anaesth. 2012;6:27e30.

17. Odeberg S, Ljungquist $\mathrm{O}$, Svenberg $\mathrm{T}$, Gannedahl P, Bäckdahl M, von Rosen A, et al. Hemodynamic effects of pneumoperitoneum and the influence of posture during anesthesia for laparoscopic surgery. Acta A naesthesiol Scand. 1994;38:276-83.

18. Safran DB, Orlando R. Physiological effects of pneumoperitoneum. Am J Surg. 1994; 167:281-6.

19. Joris J, Lamy M. Neuroendocrine changes during pneumoperitoneum for laparoscopic cholecystectomy. Br J Anaesth. 1993;70:A33.

20. Feig BW, Berger DH, Doughtery TB, Dupuis JF, His B, Hickey RC, et al. Pharmacological intervention can reestablish baseline haemodynamic parameters during laparoscopy. Surgery. 1994;116:733-9.

21. Luchetti M, Palomba R, Sica G, Massa G, Tufano R. Effectiveness and safety of combined epidural and general anesthesia for laparoscopic cholecystectomy. Reg Anesth. 1996;21:465-9.

22. Lehtinen AM, Laatikainen T, Koskimies AI, Hovorka J. Modifying effects of epidural analgesia or general anesthesia on stress hormone response to laparoscopy for in vitro fertilization. J In Vitro Fert Embryo Transf. 1987;4:23-9.

23. Lerou JG, Booij LH. Model based administration of inhalational anesthesia. Developing a system model. $\mathrm{Br} \quad \mathrm{J}$ Anaesth. 2001;86:12-28.

24. Liu SS, Carpenter RL, Mackey DC, Thirlby RC, Rupp SM, Shine TS, et al. Effects of perioperative analgesic technique on rate of recovery after colon surgery. Anesthesiology. 1995;83:757-65. 